\title{
Análise de sensibilidade dos parâmetros do processo de hidrólise enzimática de bagaço de cana-de-açúcar usando planejamentos de Plackett-Burman
}

\author{
Camila P. Farjani, Aline C. da Costa.
}

\begin{abstract}
Resumo
Uma etapa crítica na produção de etanol de segunda geração a partir do bagaço da cana-de-açúcar é a hidrólise da biomassa. Devido às diferentes condições de operação, é necessário reestimar os parâmetros cinéticos do modelo e, por conta disso, realizar uma análise de sensibilidade dos mesmos. Essa análise foi realizada para o bagaço desliginificado (BAD) e mostrou que apenas um dos cinco parâmetros do modelo não possuía efeitos significativos. Foram então reestimados os outros quatro parâmetros cinéticos para o bagaço sujeito ao pré-tratamento hidrotérmico $(\mathrm{BH})$. O modelo se adequou melhor ao $\mathrm{BH}$ ao reestimar os cinco parâmetros, uma vez que a análise de sensibilidade varia de acordo com o pré-tratamento.
\end{abstract}

\section{Palavras-chave: \\ Hidrólise enzimática, Planejamento de Plackett-Burman, Evolução diferencial}

\section{Introdução}

A hidrólise enzimática é um processo utilizado em uma das etapas da produção de etanol de segunda geração. Godoy, Machado e Costa (2019) propuseram um modelo para cálculo da taxa de reação com uma elevada porcentagem de sólidos, permitindo determinar a concentração de glicose e celulose em um reator batelada. $O$ modelo conta com cinco parâmetros, $k, K_{M}$, $K_{I G}$, a e $n$, sendo que os três primeiros representam a constante da taxa de reação, a constante de saturação da celulose e a constante de inibição da glicose, respectivamente. $K_{I G}$, a e $n$ são utilizados no cálculo de uma constante de inibição modificada. Objetiva-se realizar uma análise de sensibilidade dos parâmetros deste modelo e reestimá-los para um diferente prétratamento do bagaço da cana-de-açúcar.

\section{Resultados e Discussão}

A partir de planejamentos fatoriais de Plackett-Burman e de simulações com o modelo matemático, foram determinados os parâmetros cinéticos que possuíam maiores efeitos para o bagaço desliginificado (BAD), para diferentes concentrações de sólidos e diferentes tempos de reação. Este estudo foi realizado a partir das concentrações de glicose e de celulose, alterando os parâmetros entre $+10 \%$ e $-10 \%$ e entre $+20 \%$ e $-20 \%$.

Pelos valores encontrados para os efeitos, foi possível observar que os impactos nas concentrações de glicose e de celulose são semelhantes, alternando se o efeito era positivo ou negativo. Também, os efeitos para $20 \%$ de variação foram aproximadamente proporcionais aos para $10 \%$. Logo, as análises feitas com essa última variação são representativas.

O efeito do parâmetro $n$, em geral, aumentou significativamente ao longo do tempo e com o aumento da porcentagem de sólidos, se destacando em relação aos demais. Por estar relacionado à inibição, já era esperado que seu efeito aumentasse com uma maior porcentagem de sólidos.

Considerando um nível de $95 \%$ de confiança, somente um dos parâmetros, a, não apresentou efeitos significativos. Assim, para reestimar os parâmetros para o bagaço sujeito ao pré-tratamento hidrotérmico $(\mathrm{BH})$ através da metodologia da Evolução Diferencial, seu valor foi fixado. Foram utilizados os dados experimentais disponibilizados por Godoy, Machado e Costa (2019) para $5 \%, 15 \%$ e $20 \%$ de sólidos. Além do resíduo, a validade do ajuste foi confirmada através da comparação dos valores experimentais e os calculados pela modelagem com os parâmetros reestimados, considerando $10 \%$ de sólidos.

Observou-se que um melhor ajuste poderia ser obtido através da variação dos cinco parâmetros cinéticos, incluindo $a$, já que os efeitos variam de acordo com o pré-tratamento do bagaço (GODOY; MACHADO; COSTA, 2019). Isso resultou em valores diferentes para os parâmetros a e $n$ em relação aos apresentados por Godoy, Machado e Costa (2019). Ainda, os intervalos de confiança obtidos para dois dos parâmetros $\left(K_{M}\right.$ e $\left.K_{/ G}\right)$ incluíram o valor zero, o que indica alto nível de incerteza destes parâmetros. Contudo, três intervalos de confiança referentes aos valores originais dos parâmetros incluíam o zero (GODOY; MACHADO; COSTA, 2019).

\section{Conclusões}

Pôde-se observar que os efeitos dos parâmetros do modelo podem ser analisados a partir dos valores das concentrações de glicose ou celulose e que a variação de $10 \%$ dos parâmetros nos planejamentos fatoriais de Plackett-Burman é representativa.

Pela análise de sensibilidade, examinou-se que um dos parâmetros possuía um efeito muito elevado no modelo cinético em relação aos demais, o que pode ser inadequado. Além disso, evidenciou-se a influência da porcentagem de sólidos nos efeitos dos parâmetros.

A reestimativa para $0 \mathrm{BH}$ pela Evolução Diferencial fixando a não teve resultados satisfatórios, sendo preferível o ajuste original já proposto por Godoy, Machado e Costa (2019). Com isso, foi possível observar a influência do pré-tratamento do bagaço nos efeitos dos parâmetros. Os valores obtidos ao reestimar os cinco parâmetros se mostraram mais adequados, diminuindo os resíduos e a incerteza em comparação com o ajuste de Godoy, Machado e Costa (2019).

\section{Agradecimentos}

Agradecimentos ao $\mathrm{CNPq}$ pelo financiamento e à Carolina Marion de Godoy por todo auxílio prestado.

GODOY, Carolina Marion de; MACHADO, Daniele Longo; COSTA, Aline Carvalho da. Batch and fed-batch enzymatic hydrolysis of pretreated sugarcane bagasse-Assays and modeling. Elsevier. Campinas, p. 392-399. maio 2019. 